\title{
Neural processing of criticism and positive comments from relatives in individuals with schizotypal personality traits
}

\author{
PREETHI PREMKUMAR ${ }^{1,2}$, STEVEN CR WILLIAMS ${ }^{3}$, DAVID LYTHGOE $^{3}$, \\ CHRISTOPHER ANDREW ${ }^{3}$, ELIZABETH KUIPERS ${ }^{1,4 \dagger} \&$ VEENA KUMARI $^{1,4 \dagger}$ \\ ${ }^{1}$ Department of Psychology, Institute of Psychiatry, King's College London, London, UK, ${ }^{2}$ Department of Psychology, \\ Nottingham Trent University, Nottingham, UK, ${ }^{3}$ Centre for Neuroimaging Sciences, Institute of Psychiatry, King's College \\ London, London, UK, and ${ }^{4}$ NIHR Biomedical Research Centre for Mental Health, South London and Maudsley NHS \\ Foundation Trust, London, UK
}

\begin{abstract}
Objectives. High negative expressed emotion by family members towards schizophrenia patients increases the risk of subsequent relapse. The study aimed to determine whether individuals with high schizotypy (HS) and low schizotypy (LS) would differ in activation of brain areas involved in cognitive control when listening to relative criticism. Methods. Twelve HS and 12 LS individuals listened to relative's critical, positive and neutral comments about them while undergoing functional MRI. Activation maps in the two groups during the comments were compared using SPM5. Results. The left superior frontal and middle frontal gyri and bilateral posterior cingulate cortex were activated during criticism, compared to neutral comments, across all participants. While there were no group differences in brain activity for criticism versus neutral comments, the HS group, who had lower current mood relative to the LS group, activated to a lesser extent the thalamus, insula, putamen and brain stem during positive, compared to neutral, comments. Conclusions. Listening to relative criticism in healthy individuals engages brain areas for cognitive control of negative emotion and self-referential processing. However, HS individuals may have an attenuated ability to respond to rewarding aspects of positive comments due to their lower current mood.
\end{abstract}

Key words: Schizotypal personality, expressed emotion, frontal lobe, reward, thalamus

\section{Introduction}

Stressors interact with pre-existing vulnerability to psychosis to trigger a psychotic episode (Rosenfarb et al. 1995). One such stressor is negative expressed emotion (NEE) by a family member (Brown and Rutter 1966; Vaughn and Leff 1976; Kuipers 1979). People with schizophrenia may have increased sensitivity to NEE than normal (Bachmann et al. 2006). Furthermore, high NEE in close relatives increases the likelihood of psychiatric relapse (Brown and Rutter 1966; Bebbington and Kuipers 1994). In patients with psychosis, a high level of relative criticism is related to longer hospital stay (Marom et al. 2005) and high depression and anxiety in patients (Docherty et al. 2009).

One reason for the development of negative, critical relationships is that the relative attempts to control events through restoring or changing patient behaviour (Greenley 1986). Kuipers and colleagues (2007) found that discrepancies between the patient and their relative in their views about whether anything could be done to improve the illness related to greater depression and lower self-esteem in carers, but not to NEE status. In contrast, Lobban and colleagues (2006) did find that greater patient-relative discrepancy in illness perception was related to high NEE.

\section{Neural basis of EE}

Studying the neural response to relative criticism might elucidate how patients interpret and cope with high NEE in terms of the salience patients attach to criticism. It may lead to greater understanding of 
how emotional information might be encoded, stored and appraised (Kompus et al. 2009). The dorsolateral prefrontal cortex (DLPFC) is thought to play a key role in integrating emotional and cognitive information (Gray et al. 2002; Pessoa 2008) and exerting cognitive control (the use of executive functions to regulate information processing (Minzenberg et al. 2009) over, or reappraisal of negative emotional stimuli (Herwig et al. 2007; Mak et al. 2009). Similarly, the rostral anterior cingulate cortex (ACC) is involved in appraisal of emotional information (Ochsner and Gross 2005; Kalisch et al. 2006; Polli et al. 2008), specifically negatively valenced material (Kalisch et al. 2006; Mak et al. 2009), as well as conflict detection during tasks such as emotional Stroop interference (Mohanty et al. 2007). The posterior cingulate cortex (PCC) is involved in cognitive control of aversive stimuli (Koenigsberg et al. 2010) and self-evaluation (Pyka et al. 2009; Sajonz et al. 2010). In contrast, response to positively valenced material may engage dopaminergic reward areas, such as the striatum. Dorsal and ventral striatum have been reported to be activated when viewing positive words (Hamann and Mao 2002), ventral striatum when listening to pleasant music (Mitterschiffthaler et al. 2007), and ventral striatum and midbrain when viewing pleasant statements (Colibazzi et al. 2010) in healthy participants.

A small number of studies have investigated the neural basis of expressed emotion sensitivity in psychiatric populations. Formerly depressed patients, compared to healthy participants, failed to activate the DLPFC and ACC when listening to maternal criticism and praise (Hooley et al. 2009). Schizophrenia patients were found to activate the lateral middle frontal gyrus, rostral ACC, inferior frontal gyrus, temporal pole and insula when listening to relative criticism compared to relative's or stranger's neutral comments (Rylands et al. 2011); this study did not include a control group.

\section{EE and schizotypy}

Studying the neural effects of EE in individuals with a schizotypal personality can be argued as being a first step in investigating the multi-factorial processes probably involved in managing negative NEE response, without having to deal with the confounds of morbidity, medication and hospitalization in patients with psychosis. Schizotypy is a personality trait within the normal range of the schizophrenia spectrum. Schizotypal traits include magical thinking, unusual perceptual experience, odd behaviour and speech (Mason et al. 1995) that are thought to correspond to positive symptoms of psychosis (Mason et al. 2005; Cochrane et al. 2010). Anhedonia in schizotypal individuals is thought to correspond to some negative symptoms in psychosis patients (Vollema and van den Bosch 1995). Individuals with schizotypal traits may also resemble schizophrenia patients in terms of genetics (Fanous et al. 2001; Fanous et al. 2007), neuropsychological ability (Ettinger et al. 2005; Gooding et al. 2006) and neurobiology (Kumari et al. 2004; Bollini et al. 2007; Kumari et al. 2008).

Studying NEE in individuals within the normal range of the schizophrenia spectrum might help to understand whether NEE exists before illness onset. Recent studies of the early onset of psychosis suggest that NEE can develop as a result of the problems manifested by the young person developing a psychotic disorder rather than it being a trait of family members (McFarlane and Cook 2007). Other studies show that NEE can be triggered rapidly by these difficulties even in first episodes (Raune et al. 2004). Another possibility is that NEE may reflect ongoing difficulties in the relatives, exacerbated by the undoubted stress of the caring role (Hooley and Hiller 2000).

\section{Aims and hypotheses}

The main aim of the study was to determine whether individuals with high (HS group) and little or no schizotypy (LS group) would differ in the level of activation of brain areas that are involved in cognitive control when listening to relative criticism and positive comments. The relative was defined as a parent, sibling or partner who had at least $10 \mathrm{~h}$ per week contact, either living together or in phone contact, with the participant. It was hypothesized that compared to the LS group, the HS group may show (a) increased activity in response to relative criticism in the brain regions normally associated with cognitive control of emotional stimuli, namely DLPFC, rostral ACC and PCC (Gray et al. 2002; Pessoa 2008; Kompus et al. 2009), and (b) decreased activity of reward areas during positive comments due to lower mood (Vollema and van den Bosch 1995). The DLPFC is over-activated in schizophrenia patients during cognitive control of emotional stimuli (Park et al. 2008). The rostral ACC has been found to be activated during relative criticism in schizophrenia patients (Rylands et al. 2011). The PCC is involved in self-referential processing (Kumari et al. 2010; Sajonz et al. 2010) and the HS group may engage in more reflective processing of criticism than the LS group, due to greater past exposure to high NEE. Greater anhedonia severity is associated with lower activity of reward centres, namely ventral striatum and insula, during positively valenced emotion processing in schizophrenia and 
healthy populations (Harvey et al. 2007, 2010). A further hypothesis was that the HS group would be more likely to have a high NEE relative than the LS group, as high NEE is an environmental stressor that precipitates a person's pre-existing vulnerability to psychosis (Rosenfarb et al. 1995).

\section{Methods}

\section{Participants and design}

Participants were drawn from the general population. Twelve participants had high (HS group) and 12 had low schizotypy (LS group). High schizotypy was defined as score $\geq 7$, and low schizotypy as score $\leq 2$, on the Unusual Experiences (UE) subscale of the short form of the Oxford and Liverpool Inventory of Feelings and Experiences (O-LIFE) (Mason et al. 2005). The UE subscale of the O-LIFE was chosen to identify HS and LS participants, as a high score on this subscale is associated with greater positive symptom severity in schizophrenia patients (Cochrane et al. 2010). A criterion of $\geq 7$ out of a maximum score of 12 on the UE subscale on the O-LIFE short form for HS was based on $\geq 1 \mathrm{SD}$ above the normal population of the UE subscale (Mason et al. 2005). A score of $\geq 7$, out of a maximum score of 12 , on the UE subscale on the O-LIFE short form represents $58 \%$ of the maximum possible score. This score would correspond to a score of $\geq 21$, out of 36 , on the UE subscale of the O-LIFE extended form (Mason et al. 1995) that is similar to average UE scores found in high schizotypy groups in other studies (Morgan et al. 2006; Morgan et al. 2009; Barkus et al. 2011). A score of $\leq 2$ on the UE subscale on the O-LIFE short form represents $16 \%$ of the maximum possible score. This score would correspond to $\leq 6$ on the UE subscale of the O-LIFE extended form which is similar to or lower than the average UE scores for low schizotypy groups in other studies (Morgan et al. 2006; Morgan et al. 2009; Barkus et al. 2011). The other O-LIFE subscales, namely cognitive disorganisation, introvertive anhedonia and impulsive non-conformity, were also administered for sample characterisation purposes.

Potential participants were chosen from a database of healthy volunteers (MindSearch, Institute of Psychiatry; $n \geq 500$ ) and by circular emails sent to staff and students of King's College London, UK. Inclusion criteria were: (i) IQ $>90$, estimated as a score of more than five correct responses on the National Adult Reading Test (Nelson and Wilson 1991) which corresponds to a predicted full-scale IQ of 90, (ii) right-handed, (iii) $18-45$ years age range, (iv) normal-to-corrected vision and normal hearing, and (v) a relative (parent, sibling or partner) was willing to take part in the study. Exclusion criteria were: (i) Beck Depression Inventory-II (BDI-II) (Beck et al. 1996) score $\geq 30$, i.e. severe depression, (ii) a history of mental disorder, brain injury, neurological disorder, learning disability, or loss of consciousness for more than $5 \mathrm{~min}$, and (iii) a history of alcohol or drug abuse within the last 12 months.

The relative was invited to take part in a semistructured one-hour interview (Camberwell Family Interview, CFI) (Vaughn and Leff 1976) concerning the emotional climate between household members and the participant during the last three months in order to assess relative expressed emotion. The interview was conducted by the lead author (PP) and rated for expressed emotion (Vaughn and Leff 1976). The lead author (PP) had been trained in assessment of expressed emotion by Dr Christine Vaughn, one of the developers of expressed emotion rating of the CFI, to an acceptable level of reliability (overall expressed emotion, $\Phi=0.82$; critical comments, $\Phi=0.59$, hostility, $\Phi=1.00$, emotional over-involvement, $\Phi=0.80$, warmth, $\Phi=0.71$, positive comments, $\Phi=0.82$ ). Relatives were classified as high NEE if they had ratings of $\geq 6$ critical comments, hostility as generalization and/or rejection, and/or $\geq 3$ on emotional over-involvement.

The relative was asked to write five criticisms, five positive comments and 10 neutral comments about the participant, each comment lasting for approximately $30 \mathrm{~s}$ when spoken. The emotional valence of critical and positive comments was consistent with expressed emotion criteria (Vaughn and Leff 1976). Neutral comments did not have emotional valence and related to the participant's daily routines. The relative was instructed to read critical comments in a critical tone, positive comments in a warm (positive) tone and neutral comments using a relatively flattened tone, in order to ensure that the comments heard by participants met expressed emotion criteria (see Supplementary material available online at http://informahealthcare. com/doi/abs/10.3109/15622975.2011.604101, text for examples of comments).

Participants completed the Positive and Negative Affect Scale (PANAS) (Watson et al. 1988) - moment subscale before and after the scanning session. The PANAS contains 10 positive (e.g., interested, proud) and 10 negative (e.g., ashamed, irritable) mood descriptors relating to six time points, namely moment, today, past few days, past few weeks, year and general. Participants also completed the Beck Anxiety Inventory (BAI) (Beck and Steer 1993) and Perceived Criticism Scale (PCS) (Hooley and Teasdale 1989) where the participant answered the question "How critical is your relative of you?" on an 11-point scale from 0 (not at all critical) to 10 (very critical). 
Study procedures were approved by the King's College London Research Ethics Committee (CREC/07/08-66). Participants and their relative provided written informed consent to their participation and were compensated for their time and travel.

\section{$f M R I$}

Paradigm and procedure. Participants listened to relative criticism and positive comments in two separate tasks, using two separate but identical scanning protocols. The two tasks (criticism, positive comments) were separated by an SPGR scan that lasted for 6 min and $4 \mathrm{~s}$. The criticism task consisted of five criticisms alternated with five neutral comments. The positive comments task consisted of five positive comments alternated with five neutral comments. Whether the participant was presented with the criticism task or positive comments task first was determined by a randomisation list. Within a comment block, after each comment (duration $=30 \mathrm{~s}$ ), the participant answered two questions, "How important is your relative's comment about you?" on an 11-point visual analogue scale (VAS) ranging from -5 (not at all important) to +5 (very important) by pressing left or right on a button-box (duration $=5 \mathrm{~s}$ ), and "How does your relative's views about you make you feel?", also rated on a VAS ranging from -5 (negative) to +5 (positive) (duration $=5 \mathrm{~s}$ ). The first question was thought to elicit the participant's cognitive appraisal of the comment and the second question, the participant's emotional response. Each 40-s comment block was followed by a 20 -s rest block.

Image acquisition. Echo-planar $\mathrm{T} 2{ }^{\star}$-weighted $\mathrm{MR}$ images of the brain were acquired using a 1.5 Tesla GE Signa HDx scanner (General Electric, Milwaukee WI, USA) at the Centre for Neuroimaging Sciences, Institute of Psychiatry, King's College London. A localiser scan for placing the volume of interest and a high-resolution structural scan for image co-registration were acquired. An eight channel radio frequency head coil working in parallel mode was used to acquire images from each of 36 near-axial non-contiguous planes parallel to the inter-commissural plane. These $M R$ images depicting BOLD contrast were acquired with an echo time $(\mathrm{TE})=40 \mathrm{~ms}$, repetition time $(\mathrm{TR})=2.5 \mathrm{~s}$, field of view $=24 \mathrm{~cm}$, flip angle $=85^{\circ}$, in-plane resolution $=3.75 \mathrm{~mm}$, slice thickness $=3$ $\mathrm{mm}$, interslice ga $P=0.3 \mathrm{~mm}$. For each task (criticism, positive comments), four dummy scans to allow magnetisation to reach a steady state followed by 240 volumes were acquired, resulting in a total scan time of $10 \mathrm{~min}$ and $10 \mathrm{~s}$ for each task. An inversion recovery prepared fast 3D structural scan was acquired
$(\mathrm{TR}=11.1 \mathrm{~ms}, \mathrm{TE}=4.9 \mathrm{~ms}$, inversion time $=300 \mathrm{~ms}$, acquisition matrix $=256 \times 160,150$ locations, slice thickness $=1.1 \mathrm{~mm}$, in-plane resolution $=1.094 \mathrm{~mm}$, flip angle $=18^{\circ}$, total scan time $6 \mathrm{~min}$ and $4 \mathrm{~s}$ ).

\section{Statistical analysis}

Demographic characteristics and ratings of the comments task in the HS and LS groups

In participants. Chi-squared test measured group differences in gender distribution. For continuous variables (Table I), analysis of variance (ANOVA) or Mann-Whitney $U$-test determined statistical significance of group differences. A group (HS, LS) $\times$ mood (positive, negative) $\times$ time (before and after scanning) repeated-measures ANOVA was performed for the PANAS moment scores, as well as individual one-way ANOVAs or Mann-Whitney $U$-tests for each mood at each time point to test for main effects. Given small sample sizes, there was limited power for significant $P$ values; therefore for variables where the statistical analysis of group differences resulted in a $P$ value $\leq 0.2$, effect size (Cohen's $d$ ) was also used to determine whether the size of the difference between groups in continuous variables was small (Cohen's $d<0.5$ ), medium $(\geq 0.5$ and $<0.8)$ or large $(\geq 0.8)$.

A group difference in on-line VAS ratings of importance ("not at all important" to "very important") and feeling ("very negative" to "very positive") of the criticism, positive and neutral comments was tested using ANOVA. Pearson correlations were performed between participant PCS scores and participant BDI-II, and BAI scores.

In relatives. Group (HS and LS groups) differences in relative BDI-II, BAI and number of critical comments, positive comments, hostility and warmth during the CFI were tested using ANOVA or MannWhitney $U$-test and overall expressed emotion rating using Chi-squared test (Table I). In addition based on expressed emotion rating (Vaughn and Leff 1976), relatives were classified as high or low NEE. Differences between high and low NEE groups in participant and relative BDI-II and BAI scores, were tested using ANOVA or Mann-Whitney $U$-test.

Statistical significance level was set a priori at $P$ value $\leq 0.05$; analysis of behavioural data was carried out using Statistical Package for Social Sciences (SPSS, version 16).

\section{fMRI pre-processing}

For each participant, the 240 volume functional time series images acquired during each task were motion 
Table I. Demographic and behavioural characteristics of high (HS) and low (LS) schizotypy groups.

\begin{tabular}{|c|c|c|c|c|c|c|}
\hline Characteristic & HS $(n=12)$ & LS $(n=12)$ & Test & $\chi^{2}$ or $z(\mathrm{df})$ & $P$ & $\begin{array}{l}\text { Effect size } \\
(\text { Cohen's } d)\end{array}$ \\
\hline Gender: male/female (n) & $3 / 9$ & $2 / 10$ & $\chi^{2}$ & $0.253(1)$ & 0.615 & - \\
\hline Parental socio-economic status (n) & & & M-W U & $0.676(1)$ & 0.499 & - \\
\hline Professional & 6 & 4 & & & & \\
\hline Intermediate & 5 & 7 & & & & \\
\hline Skilled & 0 & 1 & & & & \\
\hline \multirow[t]{2}{*}{ Semi-skilled } & 1 & 0 & & & & \\
\hline & Mean (SD) & Mean (SD) & & $F$ or $z(\mathrm{df})$ & & \\
\hline Age in years & $30.00(10.58)$ & $28.58(6.08)$ & ANOVA & $0.162(1,22)$ & 0.692 & 0.165 \\
\hline Years in education & $16.67(3.05)$ & $16.92(1.50)$ & M-W U & $0.089(1)$ & 0.929 & 0.104 \\
\hline \multicolumn{7}{|l|}{ O-LIFE } \\
\hline Unusual experiences & $8.17(2.33)$ & $1.00(0.95)$ & M-W U & $4.203(1)$ & $<0.001$ & 4.030 \\
\hline Cognitive disorganisation & $5.83(2.98)$ & $2.83(2.98)$ & ANOVA & $6.082(1,22)$ & 0.022 & 1.007 \\
\hline Introverted anhedonia & $1.00(1.13)$ & $1.33(0.98)$ & ANOVA & $0.595(1,22)$ & 0.449 & 0.312 \\
\hline Impulsive non-conformity & $4.50(2.47)$ & $2.33(1.61)$ & ANOVA & $6.477(1,22)$ & 0.018 & 1.041 \\
\hline Total & $18.92(5.81)$ & $7.50(5.21)$ & ANOVA & $25.682(1,22)$ & $<0.001$ & 2.015 \\
\hline Participant BDI-II & $7.75(6.70)$ & $5.58(5.84)$ & ANOVA & $0.713(1,22)$ & 0.408 & 0.345 \\
\hline Participant BAI & $10.50(9.93)$ & $5.92(5.45)$ & M-W U & $0.754(1)$ & 0.451 & 0.572 \\
\hline PANAS moment change before to after scanning & & & ANOVA & $1.452(1,22)$ & 0.241 & \\
\hline Positive - before comments task & $30.50(10.71)$ & $29.67(9.36)$ & ANOVA & $0.080(1,22)$ & 0.780 & 0.082 \\
\hline Positive - after comments task & $28.08(12.31)$ & $25.67(11.35)$ & ANOVA & $0.217(1,22)$ & 0.645 & 0.203 \\
\hline Negative - before comments task & $14.50(4.52)$ & $11.33(1.61)$ & M-W U & $2.134(1,22)$ & 0.021 & 0.934 \\
\hline Negative - after comments task & $15.58(7.86)$ & $11.08(1.38)$ & M-W U & $1.521(1,22)$ & 0.128 & 0.797 \\
\hline $\begin{array}{l}\text { Perceived Criticism Scale: How critical is your } \\
\text { relative of you? (11-point scale) }\end{array}$ & $5.00(3.16)$ & $4.00(3.13)$ & ANOVA & $0.606(1,22)$ & 0.445 & 0.318 \\
\hline \multicolumn{7}{|l|}{ Relative } \\
\hline \multicolumn{7}{|l|}{ Type of relative $(n)$} \\
\hline Partner & 9 & 8 & & & & \\
\hline Parent & 1 & 1 & & & & \\
\hline Sibling & 2 & 3 & & & & \\
\hline Relative BDI-II & $7.58(6.15)$ & $9.00(5.15)$ & ANOVA & $0.374(1,22)$ & 0.547 & 0.250 \\
\hline Relative BAI & $7.67(6.89)$ & $5.08(3.92)$ & ANOVA & $1.274(1,22)$ & 0.271 & 0.462 \\
\hline \multicolumn{7}{|l|}{ CFI rating } \\
\hline \multirow[t]{2}{*}{ EE level: high/low $(n)$} & $7 / 5$ & $2 / 10$ & $\chi^{2}$ & $4.444(1)$ & 0.035 & - \\
\hline & Mean (SD) & Mean (SD) & & $F$ or $\mathrm{z}(\mathrm{df})$ & & \\
\hline Number of critical comments & $4.50(2.50)$ & $3.27(2.24)$ & ANOVA & $1.523(1,22)$ & 0.231 & 0.518 \\
\hline Hostility & & & M-W U & $2.160(1)$ & 0.031 & - \\
\hline No hostility & 5 & 10 & & & & \\
\hline Hostility as generalisation & 5 & 2 & & & & \\
\hline Hostility as rejection & 2 & 0 & & & & \\
\hline $\begin{array}{l}\text { Emotional over-involvement } \\
(0=\text { none to } 5=\text { marked })\end{array}$ & 0 & 0 & - & - & - & - \\
\hline Number of positive comments & $2.25(2.38)$ & $2.00(3.05)$ & ANOVA & $0.050(1,22)$ & 0.825 & 0.090 \\
\hline Warmth $(0=$ no warmth to $5=$ high warmth $)$ & $2.58(1.56)$ & $3.17(0.83)$ & M-W U & $1.180(1,22)$ & 0.266 & 0.470 \\
\hline
\end{tabular}

BAI, Beck Anxiety Inventory; BDI-II, Beck Depression Inventory - version II; CFI, Camberwell Family interview; M-W U, Mann-Whitney $U$-test; O-LIFE, Oxford and Liverpool Inventory of Feelings and Experiences; PANAS, Positive and Negative Affect Scale.

corrected, transformed into stereotactic space (Montreal Neurological Institute, MNI), smoothed with an $8 \mathrm{~mm}$ FWHM Gaussian filter and band pass filtered using statistical parametric mapping software (SPM, version 5-1782, 2008; http://www.fil.ion.ucl. ac.uk/spm).

\section{Statistical inferences for fMRI data}

Data were analysed using the General Linear Model within SPM. At the single-subject level, contrast maps of the two conditions (criticism/positive comments and neutral comments) for the two tasks were created, covarying for motion parameters, with the 20-s rest period as the implicit baseline. This procedure was carried out by modelling each condition at each voxel using a boxcar function across the whole brain which incorporates the delay inherent in the hemodynamic response. The resulting maps were entered into a random-effects procedure at the second level to investigate task condition-related activation differences across the whole brain using height threshold $P<0.005$, cluster uncorrected $P<0.05$ (i) across all participants using one sample $t$-tests, and (ii) between 
Table II. Participant and relative BDI and BAI scores, mean (SD), based on high and low negative expressed emotion groups.

\begin{tabular}{|c|c|c|c|c|c|c|}
\hline $\begin{array}{l}\text { BDI or } \\
\text { BAI score }\end{array}$ & $\begin{array}{l}\text { High NEE } \\
\quad(n=9)\end{array}$ & $\begin{array}{l}\text { Low NEE } \\
(n=15)\end{array}$ & Test & $F$ or $z(\mathrm{df})$ & $P$ & $\begin{array}{l}\text { Effect size } \\
\text { (Cohen's } d \text { ) }\end{array}$ \\
\hline Participant BDI & $6.56(7.21)$ & $6.73(5.86)$ & ANOVA & $0.004(1,22)$ & 0.948 & 0.026 \\
\hline Participant BAI & $6.56(8.17)$ & $9.20(8.30)$ & ANOVA & $0.577(1,22)$ & 0.455 & 0.320 \\
\hline Relative BDI & $8.56(6.95)$ & $8.13(4.88)$ & ANOVA & $0.031(1,22)$ & 0.863 & 0.072 \\
\hline Relative BAI & $9.22(7.36)$ & $4.65(3.60)$ & M-W U & $1.44(1)$ & 0.155 & 0.789 \\
\hline
\end{tabular}

BDI, Beck Depression Inventory version II; BAI, Beck Anxiety Inventory; M-W U, Mann-Whitney U-test; NEE, negative expressed emotion.

HS and LS groups using SPM ANOVA. One HS participant was excluded from the critical comments task fMRI analysis due to the poor quality of the fMRI data.

Correlation between neural response to comments and subjective ratings of comments, mood and perceived criticism

Subject-specific average activation values from all clusters showing significant task-related activation changes across all participants were extracted using MarsBaR (http://marsbar.sourceforge.net/projects/ marsbar) and examined in SPSS for their relation to the relevant VAS ratings of the comments, mood and PCS rating using Pearson correlations. Due to the large number of correlational analyses that were performed, correlations with $P$ value $\leq 0.001$ were considered significant.

\section{Results}

Demographic and behavioural characteristics of participants

In both groups, participants were mostly female and groups were matched in age, years in education and depression (Table I). Besides the O-LIFE UE subscale $(P<0.0001)$, the HS group had higher cognitive disorganisation $(P=0.022)$ and impulsive non-conformity $(P<0.0001)$ than the LS group. The groups did not differ in self-reported depression, PCS rating or change in positive and negative mood before and after the scan, but the HS group had more negative mood than the LS group both before and after the scan $(P=0.021$ and 0.128 , respectively, but large effect sizes). Higher PCS rating was related to higher participant BDI-II score $(r=0.466, P=0.02)$, but not participant BAI score $(r=0.156, P=0.467)$.

\section{Expressed emotion ratings and behavioural characteristics of relatives}

Comparison based on HS and LS groups. The HS group was more likely to have a high NEE relative who expressed more hostility than did the LS group (Table I). Relative depression and anxiety levels were similar between HS and LS groups, the mean being in the non-clinical range (Table I).

Comparison based on high and low NEE groups. The high NEE group $(n=9)$ did not differ from the low NEE group $(n=15)$ in participant BDI-II or participant BAI scores (Table II). High and low NEE groups did not differ in relative BDI-II, but the high NEE group had higher relative BAI scores than the low NEE group ( $P=0.155$, medium effect size). The mean ratings were all in the non-clinical range.

Table III. Participant ratings, mean (SD) of relative criticism, positive comments and neutral comments.

\begin{tabular}{|c|c|c|c|c|c|}
\hline Comment type & HS $(n=12)$ & LS $(n=12)$ & $F(\mathrm{df})$ & $P$ & $\begin{array}{l}\text { Effect size } \\
\text { (Cohen's } d \text { ) }\end{array}$ \\
\hline \multicolumn{6}{|l|}{ Criticism } \\
\hline Importance & $6.75(1.47)$ & $7.13(1.20)$ & 0.491 & 0.491 & 0.283 \\
\hline Feeling & $4.78(2.27)$ & $4.00(1.84)$ & 0.862 & 0.363 & 0.377 \\
\hline \multicolumn{6}{|c|}{ Neutral comment during critical comment task } \\
\hline Importance & $5.76(1.99)$ & $5.73(2.02)$ & 0.001 & 0.976 & 0.015 \\
\hline Feeling & $6.43(1.23)$ & $6.58(1.72)$ & 0.064 & 0.803 & 0.100 \\
\hline \multicolumn{6}{|l|}{ Positive comment } \\
\hline Importance & $8.82(1.06)$ & $8.18(1.54)$ & 1.315 & 0.264 & 0.484 \\
\hline Feeling & $8.84(0.79)$ & $8.79(1.27)$ & 0.014 & 0.906 & 0.047 \\
\hline \multicolumn{6}{|c|}{ Neutral comment during positive comment task } \\
\hline Importance & $6.89(1.66)$ & $6.05(1.37)$ & 1.759 & 0.199 & 0.552 \\
\hline Feeling & $7.58(1.10)$ & $6.95(1.36)$ & 1.490 & 0.236 & 0.509 \\
\hline
\end{tabular}




\section{Subjective ratings of comments}

The HS and LS groups did not differ in ratings of importance of and feelings about criticism and neutral comments heard during the criticism task and positive comments. However, the HS group rated neutral comments heard during the positive comments task as more important and more positive on average than did the LS group $(P=0.199$ and 0.236 , respectively, but medium effect size, Table III).

\section{fMRI results: all participants}

Criticism versus neutral comments. Across all participants, the left superior and middle frontal gyri and bilateral PCC were activated more strongly during criticism compared to neutral comments (Table IV). Reduced activation during criticism, compared to neutral comments, was observed in a cluster located in the left middle temporal gyrus, a cluster with peak in the left middle temporal gyrus and extending to left insula and left transverse temporal gyrus, right lingual gyrus and cuneus and bilateral cerebellum.
Positive versus neutral comments. The right angular gyrus was activated more strongly during positive, compared to neutral, comments (Table IV). Reduced activation during positive, compared to neutral, comments was observed in the bilateral lingual gyrus, bilateral fusiform gyrus, bilateral cerebellum, bilateral midbrain and thalamus.

\section{fMRI results: high versus low schizotypy}

Criticism versus neutral comments. No cluster differentiating the HS and LS groups was present at the uncorrected threshold of $P=0.05$ (height threshold $P<0.005)$ in the criticism versus neutral comments contrast.

Positive versus neutral comments. The HS group differed from the LS group in the activity of several brain regions when listening to positive, relative to neutral, comments. These included a cluster primarily located in the left insula, extending to the left superior temporal gyrus and left inferior frontal

Table IV. Brain regions showing differences in activation between task conditions (criticism versus neutral comments and positive versus neutral comments) across all participants.

\begin{tabular}{|c|c|c|c|c|c|c|c|c|c|}
\hline \multirow[b]{2}{*}{ Region } & \multirow[b]{2}{*}{$\mathrm{BA}$} & \multirow{2}{*}{$\begin{array}{c}\text { Cluster } \\
\text { size }\end{array}$} & \multirow{2}{*}{$\begin{array}{l}\text { Cluster } \mathrm{p} \\
\text { corrected }\end{array}$} & \multirow{2}{*}{$\begin{array}{c}\text { Cluster p } \\
\text { uncorrected }\end{array}$} & \multirow[b]{2}{*}{ Side } & \multicolumn{3}{|c|}{$\begin{array}{c}\text { MNI } \\
\text { coordinates }\end{array}$} & \multirow[b]{2}{*}{ Voxel $T$} \\
\hline & & & & & & $x$ & $y$ & $z$ & \\
\hline \multicolumn{10}{|l|}{ Criticism $>$ neutral } \\
\hline Superior frontal gyrus & 8 & 260 & 0.565 & 0.046 & $\mathrm{~L}$ & -24 & 30 & 52 & 3.18 \\
\hline Middle frontal gyrus & 8 & & & & & -24 & 16 & 50 & 3.08 \\
\hline Middle frontal gyrus & 8 & & & & & -30 & 12 & 42 & 3.19 \\
\hline Posterior cingulate cortex & 31 & 234 & 0.642 & 0.056 & $\mathrm{R} / \mathrm{L}$ & 2 & -38 & 34 & 4.26 \\
\hline \multicolumn{10}{|l|}{ Criticism $<$ neutral } \\
\hline Middle temporal gyrus & 21 & 283 & 0.501 & 0.038 & $\mathrm{~L}$ & -44 & 8 & -28 & 4.60 \\
\hline Middle temporal gyrus & 21 & & & & $\mathrm{~L}$ & -44 & 0 & -36 & 4.26 \\
\hline Middle temporal gyrus & 21 & & & & $\mathrm{~L}$ & -52 & 2 & -36 & 3.57 \\
\hline Middle temporal gyrus & 21 & 354 & 0.337 & 0.022 & $\mathrm{~L}$ & -44 & -46 & 4 & 3.30 \\
\hline Insula & & & & & $\mathrm{L}$ & -38 & -36 & 18 & 3.13 \\
\hline Transverse temporal gyrus & 41 & & & & $\mathrm{~L}$ & -36 & -30 & 12 & 2.94 \\
\hline Cerebellum - Culmen & & 654 & 0.058 & 0.003 & $\mathrm{~L}$ & -14 & -50 & -18 & 3.67 \\
\hline Lingual gyrus & 18 & & & & $\mathrm{~L}$ & -10 & -78 & -4 & 3.39 \\
\hline Cerebellum - lingual & & & & & $\mathrm{R}$ & 4 & -46 & -14 & 3.39 \\
\hline Lingual gyrus & 19 & 2,623 & $<0.001$ & $<0.001$ & $\mathrm{R}$ & 28 & -78 & 0 & 5.08 \\
\hline Lingual gyrus & 19 & & & & $\mathrm{R}$ & 34 & -70 & -6 & 4.68 \\
\hline Cuneus & 18 & & & & $\mathrm{R}$ & 16 & -84 & 12 & 4.22 \\
\hline \multicolumn{10}{|c|}{ Positive comment $>$ neutral } \\
\hline Angular gyrus & 39 & 227 & 0.628 & 0.046 & $\mathrm{R}$ & 44 & -80 & 32 & 5.45 \\
\hline \multicolumn{10}{|l|}{ Positive comment $<$ neutral } \\
\hline Midbrain - red nucleus & & 1,006 & 0.005 & $<0.001$ & $\mathrm{R} / \mathrm{L}$ & 4 & -26 & -12 & 4.77 \\
\hline Thalamus & & & & & $\mathrm{R} / \mathrm{L}$ & 0 & -26 & 8 & 4.61 \\
\hline Thalamus - pulvinar & & & & & $\mathrm{R} / \mathrm{L}$ & -6 & -28 & 0 & 4.18 \\
\hline Cerebellum - declive & & 677 & 0.036 & 0.002 & $\mathrm{R}$ & 36 & -64 & -22 & 4.88 \\
\hline Cerebellum - culmen & & & & & $\mathrm{R}$ & 24 & -52 & -20 & 3.74 \\
\hline Fusiform gyrus & 19 & & & & $\mathrm{R}$ & 42 & -80 & -18 & 2.90 \\
\hline Lingual gyrus & 18 & 1,190 & 0.002 & $<0.001$ & $\mathrm{R} / \mathrm{L}$ & -2 & -84 & -14 & 5.46 \\
\hline Cerebellum - declive & & & & & $\mathrm{L}$ & -16 & -78 & -20 & 4.33 \\
\hline Fusiform gyrus & 19 & & & & $\mathrm{~L}$ & -38 & -72 & -16 & 3.69 \\
\hline
\end{tabular}

BA, Brodmann area; MNI, Montreal Neurological Institute; R, right; L, left. 


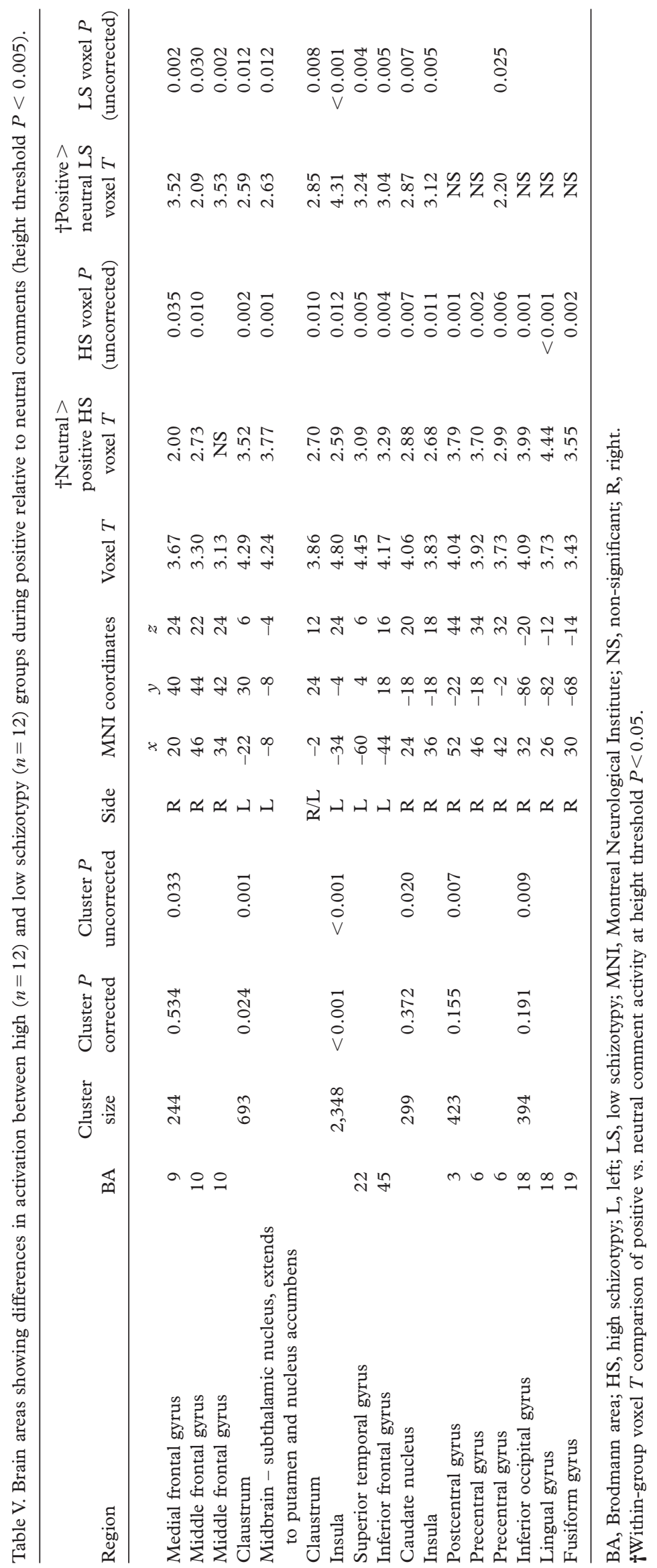


gyrus, another cluster located in the left claustrum, extending to the putamen and subthalamic nucleus of the brain stem, a cluster located in the right inferior occipital gyrus, extending to the right lingual gyrus and right fusiform gyrus, a cluster in the right thalamus and right insula, and clusters in the right precentral gyrus and right medial frontal gyrus, extending to the middle frontal gyrus (Table $\mathrm{V}$ and Figure 1). As shown in Figure 1 and within-group positive versus neutral contrast in Table V, the LS group showed activation of several brain regions, while the HS group showed decreased activation during positive, relative to neutral, comments. The HS group did not activate any brain region more strongly than the LS group during positive compared to neutral comments.

\section{Relation between neural response to comments and subjective ratings of comments, mood and perceived criticism}

Across all participants, decreased activation of the left middle temporal gyrus (maxima voxel cluster $x=-44, y=8, z=-28$ ) when listening to criticism, compared to neutral comments, was correlated with PCS rating at a near significant level after applying Bonferroni correction $(r=0.575, P=0.004)$ (Figure $2)$. No other correlation was statistically significant.

\section{Discussion}

The main aim of the study was to determine whether HS and LS groups would differ in activation level of brain areas involved in cognitive control of negative emotion when listening to relative criticism. However, this hypothesis was not supported. All participants showed greater activity in the left superior and middle frontal gyri and bilateral PCC, and lower activity in the right lingual gyrus and right cuneus, left middle and transverse temporal gyri and bilateral cerebellum during relative criticism than neutral comments. The reason for the absence of a group effect could be that the critical comments played to participants during the fMRI may not have been found to be particularly negative in the HS group. Although the HS group, as hypothesized, was more likely to have a high NEE relative than the LS group, this rating was due to generalised hostility and rejecting attitudes, not to critical comments in this sample (Table I). Some HS participants reported that they did not find the criticism they heard in the experimental task to be strongly negative, as it was based on comments that they had previously heard from their relative as part of their day-to-day interaction. Consequently, the HS group may have had a similar adaptive response to criticism to the LS group and may not have needed to engage in reappraisal of criticism more strongly than the LS group. Without prior psychiatric illness within which EE is usually contextualised, the HS group may not have had a stronger basis for reappraisal of relative criticism than the LS group; such comments may have been seen as "normal". The hypothesis that the HS group would show lower activation of reward processing areas during positive compared to neutral comments was supported however. These findings are discussed below.

\section{Increased activation of left superior and middle frontal gyri and bilateral PCC and decreased activation of right lingual gyrus during criticism across all participants}

Greater activation of the left superior and middle frontal gyri and bilateral PCC during criticism more than during neutral comments across all participants, may be explained by the role of the superior and middle temporal gyri in negative emotion regulation (Ochsner and Gross 2005; Mak et al. 2009), and the PCC in cognitive control of aversive stimuli (Koenigsberg et al. 2010), self-evaluation of past performance (Pyka et al. 2009). PCC activity is often observed in the default-mode network for working memory (Fransson and Marrelec 2008; Pyka et al. 2009), as well as self-referential processing (Kumari et al. 2010; Sajonz et al. 2010). When listening to relative criticism, individuals may engage in cognitive appraisal, rather than emotional processing, and self-reflection of such personallydirected information. Ratings of relative criticism according to expressed emotion rating criteria (Vaughn and Leff 1976) reflect dislike of particular characteristics of the participant, in addition to negative emotions such as anger or disgust. Our fMRI results suggest that participants may have been able to respond using cognitive, rather than emotional, mental processes.

Reduced activation of the right lingual gyrus and cuneus during criticism relative to neutral comments may suggest lesser use during criticism of autobiographical (Burianova and Grady 2007) and visual memory (Blondin and Lepage 2008), recognition of facial affect (Kitada et al. 2010) and verbal affect (Rama et al. 2001), as well as lesser use of mental imagery during affect recognition (Kim et al. 2007) that are normally associated with these brain regions. During neutral comments which consisted of describing the participant's general day-to-day activities (see Supplementary text available online), such as going shopping, as well as specific recent activities, such as going on holiday, information may be processed in a relatively non-affective way, such as recollection of 
66 P. Premkumar et al.

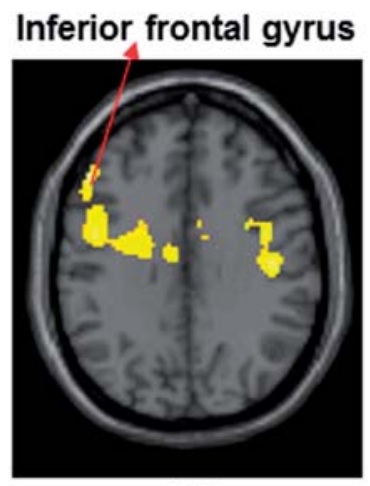

$z=16$

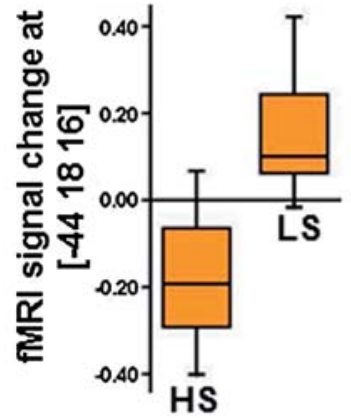

Insula

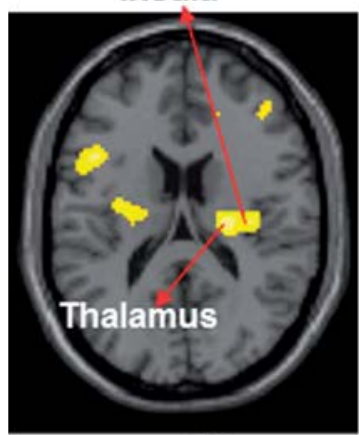

$z=18$

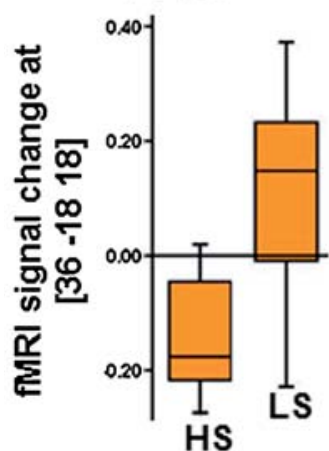

Midbrain extending to putamen
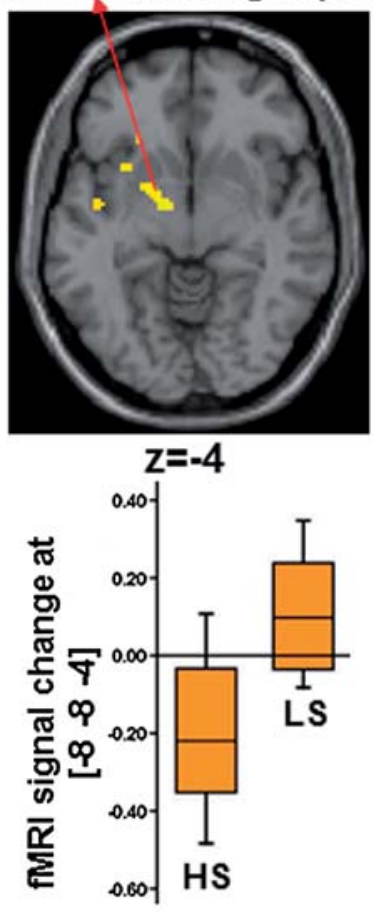

Postcentral gyrus
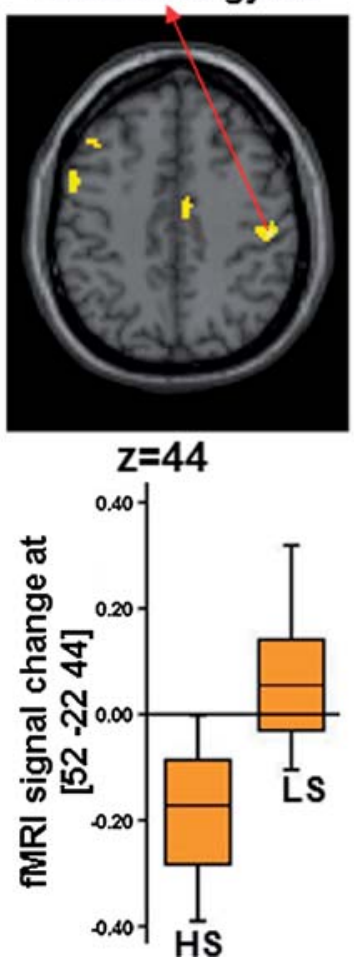

Lingual gyrus
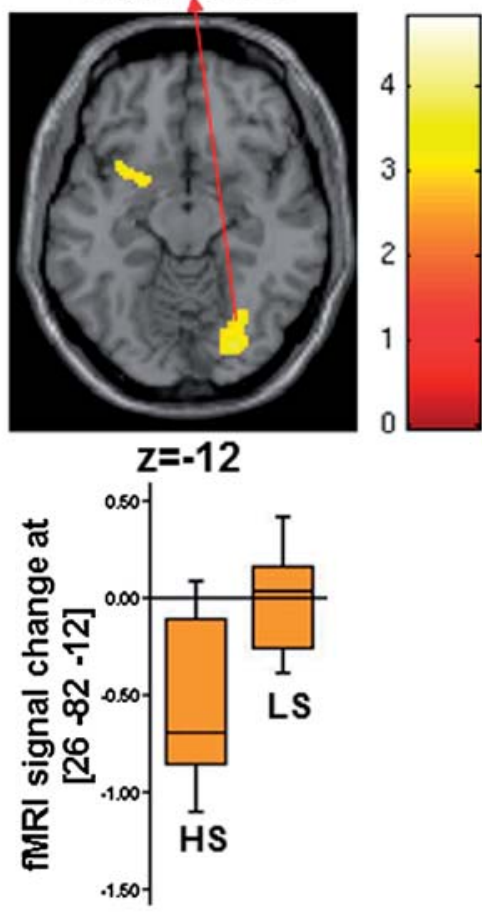

Medial/Middle frontal gyrus

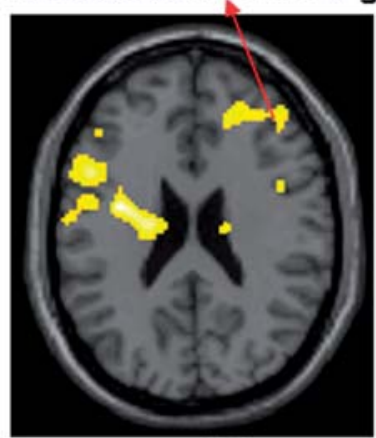

$z=24$

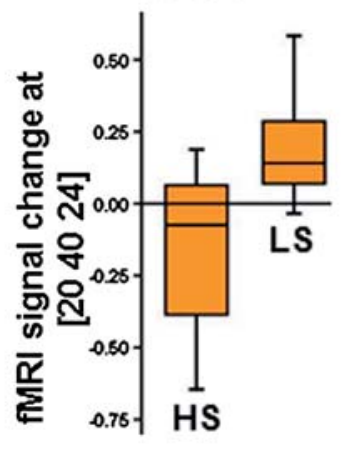

Figure 1. Maps showing activation differences in significant clusters during positive comments compared to neutral comments in high schizotypy (HS) compared to low schizotypy (LS) groups; and box plots of individual activation differences between conditions for each significant cluster within groups. Error bars represent $95 \%$ confidence intervals. 

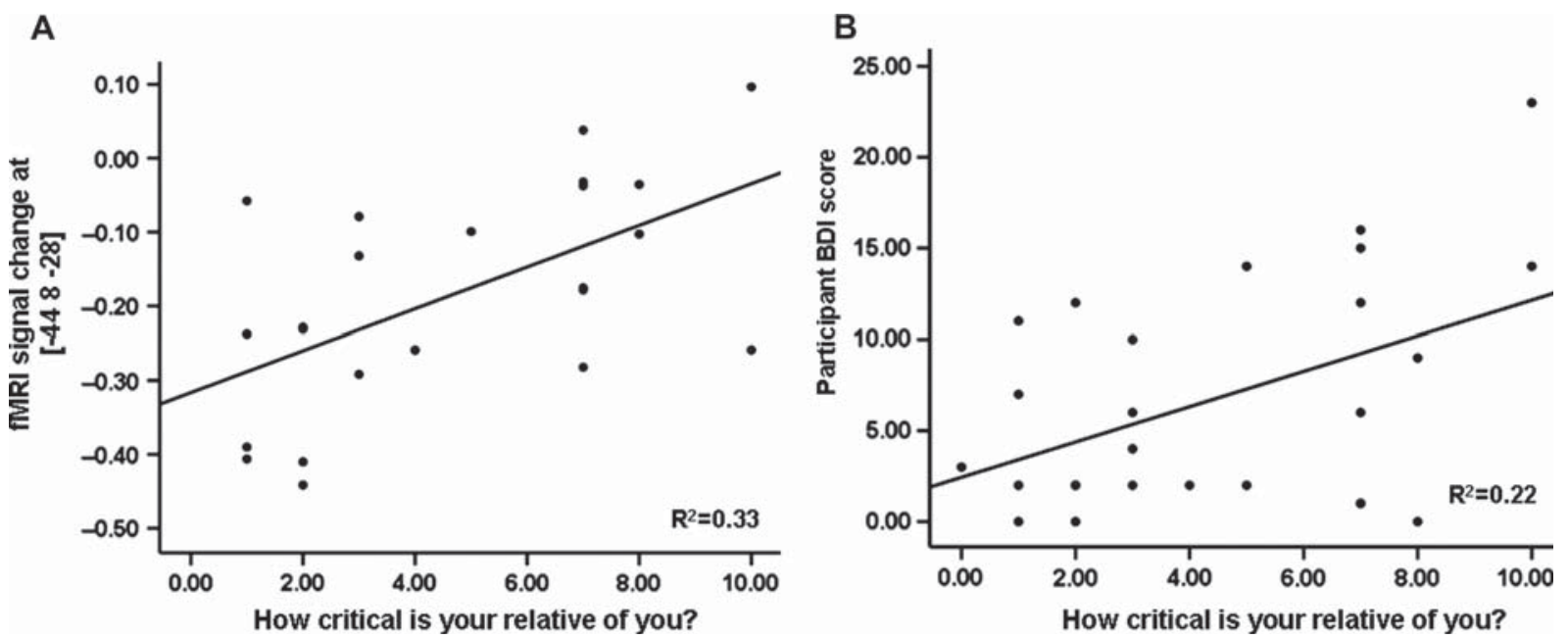

Figure 2. (A) Plot of signal change in left middle temporal gyrus (maxima voxel at $x=-44, y=8, z=-28$ ) during criticism compared to neutral comments against participant rating of the question 'How critical is your relative of you?' on an 11-point Likert scale. Across all participants, left middle temporal gyrus activation was decreased during criticism relative to neutral comments. (B) Plot of participant Beck Depression Inventory score against participant rating of the question 'How critical is your relative of you?'

routine neutral events (Nowicka et al. 2010). In contrast, the more intense negative affect contained in criticism may cause the person to concentrate on cognitive control and self-referential processing of negative emotions.

Decreased activation of a reward-processing network in the HS group while listening to positive comments

The HS group showed deactivation, while the LS group showed activation, of brain areas related to reward processing, namely the thalamus, insula, putamen and midbrain (Table V; Figure 1). A study of patients with major depression (Herwig et al. 2010) found that activation of reward-related brain regions, namely nucleus accumbens, thalamus and insula, was decreased when patients were consciously attempting to enhance their mood state in response to positive images, suggesting impaired emotional regulation function of these regions as a result of low mood. In the present study, the HS group had higher current negative mood before the scanning session than the LS group, which may partly explain why HS individuals showed diminished neural response to positive comments. Our findings suggest reduced capacity of the HS group to elevate mood in response to reward, which is consistent with findings that high anhedonia in healthy populations is associated with lower reward-related neural responsivity (Harvey et al. 2007, 2010). Some of these regions are normally activated when healthy participants are presented with positively valenced stimuli (Hamann and Mao 2002; Mitterschiffthaler et al. 2007; Colibazzi et al. 2010), while the left middle frontal gyrus (BA9) is activated during positive regulation of emotions in response to positively valenced images (Wager et al. 2008). The complex of brain areas showing lack of activity during positive comments in the HS group corresponds to the dopaminergic reward circuit that is implicated in depression (Nestler and Carlezon 2006). Therefore, the HS group may have difficulty in positive emotion regulation, given that they are more likely to experience negative mood than the LS group.

The HS group also rated on average the neutral comments that were heard in-between positive comments as more positive and important than did the LS group, although again these effects were not statistically significant. This effect may partly explain the decreased neural response to positive comments in the HS than LS group. It may be that the HS group had more difficulty in distinguishing between positive and neutral comments. It is unlikely that task order affected the HS group more than the LS group, as both groups on average rated positive and neutral comments more positively if the positive comments task was presented before the criticism task (these results are not presented). The HS group's rating of positive/neutral comments was therefore not influenced by task order any more than that of the LS group.

\section{Association between perceived level of criticism and reduced middle temporal gyrus activation during criticism}

Across all participants, a stronger perception of the relative being critical was related to lower activation of the left middle temporal gyrus during criticism compared to neutral comments. The left middle temporal gyrus is activated during detection of emotional prosody in speech (Mitchell et al. 2003) and 
integration of emotional recognition using both auditory and visual senses (Park et al. 2010). While reduced activation of the middle temporal gyrus during criticism, relative to neutral comments seems counterintuitive, it may be suggested that the left middle temporal gyrus is involved in desensitization to criticism. However, stronger perception of the relative being critical was related to a higher level of participant depression in our study. Docherty and colleagues (2009) found that in patients with schizophrenia, a higher level of relative criticism was related to higher patient anxiety when predicting the maintenance or exacerbation of patient psychotic symptom severity. The present study's findings show that higher perceived relative criticism can affect or be affected by both the person's mood and his/her neural response to relative criticism.

\section{Limitations}

The exploratory nature of the study and small sample sizes are key factors that limit the generalizability of the results. We used rather low statistical thresholds for behavioural and fMRI analysis. Only a few clusters from the comparison of positive versus neutral comments across all participants and between groups were significant after cluster-level correction for multiple comparisons. The HS and LS groups did not differ in rating of criticism and positive comments. While this finding highlights the discordance between self-reported ratings of comments and the neural response to comments, it is possible that the limited range of scores on the Likert scale $(-5$ to +5$)$ may have reduced the likelihood of yielding such group differences. Criticisms were not considered to be as intense as positive comments on average, as this was reflected in the subjective ratings of the comments made by participants (Table II).

\section{Conclusions}

Listening to criticism, relative to neutral comments, may cause people to engage brain areas for emotion regulation and thinking about oneself, rather than remembering and visualisation of recent events. High schizotypal individuals may not be able to engage reward-related brain regions while listening to positive comments to the same extent as low schizotypal individuals due to their lower current mood.

\section{Acknowledgements}

The study was supported by funds from the Biomedical Research Centre for Mental Health at the
Institute of Psychiatry, King's College London, and the South London and Maudsley NHS Foundation Trust for some of Professor Elizabeth Kuiper's clinical time.

\section{Statement of Interest}

None to declare.

\section{References}

Bachmann S, Bottmer C, Jacob S, Schroder J. 2006. Perceived criticism in schizophrenia: a comparison of instruments for the assessment of the patient's perspective and its relation to relatives' expressed emotion. Psychiatry Res 142(2-3):167-175.

Barkus E, Smallman R, Royle N, Barkus C, Lewis S, Rushe T. 2011. Auditory false perceptions are mediated by psychosis risk factors. Cogn Neuropsychiatry.

Bebbington P, Kuipers L. 1994. The predictive utility of expressed emotion in schizophrenia: an aggregate analysis. Psychol Med 24(3):707-718.

Beck AT, Steer RA. 1993. Manual for the Beck Anxiety Inventory. San Antonio, TX: Psychological Corporation.

Beck AT, Steer RA, Brown GK. 1996. Manual for the Beck Depression Inventory. San Antonion, TX: Psychological Corporation.

Blondin F, Lepage M. 2008. An fMRI study on memory discriminability for complex visual scenes. Hum Brain Mapp 29(10):1159-1169.

Bollini AM, Compton MT, Esterberg ML, Rutland J, Chien VH, Walker EF. 2007. Associations between schizotypal features and indicators of neurological and morphological abnormalities. Schizophr Res 92(1-3):32-40.

Brown GW, Rutter M. 1966. The measurement of family activities and relationships. Hum Relations 19:241-263.

Burianova H, Grady CL. 2007. Common and unique neural activations in autobiographical, episodic, and semantic retrieval. J Cogn Neurosci 19(9):1520-1534.

Cochrane M, Petch I, Pickering AD. 2010. Do measures of schizotypal personality provide non-clinical analogues of schizophrenic symptomatology? Psychiatry Res 176(2-3):150-154.

Colibazzi T, Posner J, Wang Z, Gorman D, Gerber A, Yu S, et al. 2010. Neural systems subserving valence and arousal during the experience of induced emotions. Emotion 10(3):377-389.

Docherty NM, St-Hilaire A, Aakre JM, Seghers JP, McCleery A, Divilbiss M. 2009. Anxiety interacts with expressed emotion criticism in the prediction of psychotic symptom exacerbation. Schizophr Bull 37(3):611-618.

Ettinger U, Kumari V, Crawford TJ, Flak V, Sharma T, Davis RE, Corr PJ. 2005. Saccadic eye movements, schizotypy, and the role of neuroticism. Biol Psychol 68(1):61-78.

Fanous A, Gardner C, Walsh D, Kendler KS. 2001. Relationship between positive and negative symptoms of schizophrenia and schizotypal symptoms in nonpsychotic relatives. Arch Gen Psychiatry 58(7):669-673.

Fanous AH, Neale MC, Gardner CO, Webb BT, Straub RE, O'Neill FA, et al. 2007. Significant correlation in linkage signals from genome-wide scans of schizophrenia and schizotypy. Mol Psychiatry 12(10):958-965.

Fransson P, Marrelec G. 2008. The precuneus/posterior cingulate cortex plays a pivotal role in the default mode network: Evidence from a partial correlation network analysis. Neuroimage 42(3):1178-1184. 
Gooding DC, Matts CW, Rollmann EA. 2006. Sustained attention deficits in relation to psychometrically identified schizotypy: evaluating a potential endophenotypic marker. Schizophr Res 82(1):27-37.

Gray JR, Braver TS, Raichle ME. 2002. Integration of emotion and cognition in the lateral prefrontal cortex. Proc Natl Acad Sci USA 99(6):4115-4120.

Greenley JR. 1986. Social control and expressed emotion. J Nerv Ment Dis 174(1):24-30.

Hamann S, Mao H. 2002. Positive and negative emotional verbal stimuli elicit activity in the left amygdala. Neuroreport 13(1):15-19.

Harvey PO, Pruessner J, Czechowska Y, Lepage M. 2007. Individual differences in trait anhedonia: a structural and functional magnetic resonance imaging study in non-clinical subjects. Mol Psychiatry 12(8):767-775.

Harvey PO, Armony J, Malla A, Lepage M. 2010. Functional neural substrates of self-reported physical anhedonia in nonclinical individuals and in patients with schizophrenia. J Psychiatr Res 44(11):707-716.

Herwig U, Baumgartner T, Kaffenberger T, Bruhl A, Kottlow M, Schreiter-Gasser U, et al. 2007. Modulation of anticipatory emotion and perception processing by cognitive control. Neuroimage 37(2):652-662.

Herwig U, Bruhl AB, Kaffenberger T, Baumgartner T, Boeker H, Jancke L. 2010. Neural correlates of 'pessimistic' attitude in depression. Psychol Med 40(5):789-800.

Hooley JM, Hiller JB. 2000. Personality and expressed emotion. J Abnorm Psychol 109(1):40-44.

Hooley JM, Teasdale JD. 1989. Predictors of relapse in unipolar depressives: expressed emotion, marital distress, and perceived criticism. J Abnorm Psychol 98(3):229-235.

Hooley JM, Gruber SA, Parker HA, Guillaumot J, Rogowska J, Yurgelun-Todd DA. 2009. Cortico-limbic response to personally challenging emotional stimuli after complete recovery from depression. Psychiatry Res 172(1):83-91.

Kalisch R, Wiech K, Critchley HD, Dolan RJ. 2006. Levels of appraisal: a medial prefrontal role in high-level appraisal of emotional material. Neuroimage 30(4):1458-1466.

Kim SE, Kim JW, Kim JJ, Jeong BS, Choi EA, Jeong YG, et al. 2007. The neural mechanism of imagining facial affective expression. Brain Res 1145:128-137.

Kitada R, Johnsrude IS, Kochiyama T, Lederman SJ. 2010. Brain networks involved in haptic and visual identification of facial expressions of emotion: an fMRI study. Neuroimage 49(2):1677-1689.

Koenigsberg HW, Fan J, Ochsner KN, Liu X, Guise K, Pizzarello S, et al. 2010. Neural correlates of using distancing to regulate emotional responses to social situations. Neuropsychologia 48(6):1813-1822.

Kompus K, Hugdahl K, Ohman A, Marklund P, Nyberg L. 2009. Distinct control networks for cognition and emotion in the prefrontal cortex. Neurosci Lett 467(2):76-80.

Kuipers E, Watson P, Onwumere J, Bebbington P, Dunn G, Weinman J, et al. 2007. Discrepant illness perceptions, affect and expressed emotion in people with psychosis and their carers. Soc Psychiatry Psychiatr Epidemiol 42(4):277-283.

Kuipers L. 1979. Expressed emotion: a review. Br J Soc Clin Psychol 18(2):237-243.

Kumari V, ffytche DH, Williams SC, Gray JA. 2004. Personality predicts brain responses to cognitive demands. J Neurosci 24(47):10636-10641.

Kumari V, Antonova E, Geyer MA. 2008. Prepulse inhibition and "psychosis-proneness" in healthy individuals: an fMRI study. Eur Psychiatry 23(4):274-280.

Kumari V, Fannon D, Ffytche DH, Raveendran V, Antonova E, Premkumar P, et al. 2010. Functional MRI of verbal self- monitoring in schizophrenia: performance and illness-specific effects. Schizophr Bull 36(4):740-755.

Lobban F, Barrowclough C, Jones S. 2006. Does expressed emotion need to be understood within a more systemic framework? An examination of discrepancies in appraisals between patients diagnosed with schizophrenia and their relatives. Soc Psychiatry Psychiatr Epidemiol 41(1):50-55.

Mak AK, Hu ZG, Zhang JX, Xiao ZW, Lee TM. 2009. Neural correlates of regulation of positive and negative emotions: an fmri study. Neurosci Lett 457(2):101-106.

Marom S, Munitz H, Jones PB, Weizman A, Hermesh H. 2005. Expressed emotion: relevance to rehospitalization in schizophrenia over 7 years. Schizophr Bull 31(3):751-758.

Mason O, Claridge G, Jackson M. 1995. New scales for the assessment of schizotypy. Pers Individ Differ 18(1):7-13.

Mason O, Linney Y, Claridge G. 2005. Short scales for measuring schizotypy. Schizophr Res 78(2-3):293-296.

McFarlane WR, Cook WL. 2007. Family expressed emotion prior to onset of psychosis. Fam Process 46(2):185-197.

Minzenberg MJ, Laird AR, Thelen S, Carter CS, Glahn DC. 2009. Meta-analysis of 41 functional neuroimaging studies of executive function in schizophrenia. Arch Gen Psychiatry 66(8):811-822.

Mitchell RL, Elliott R, Barry M, Cruttenden A, Woodruff PW. 2003. The neural response to emotional prosody, as revealed by functional magnetic resonance imaging. Neuropsychologia 41(10):1410-1421.

Mitterschiffthaler MT, Fu CH, Dalton JA, Andrew CM, Williams SC. 2007. A functional MRI study of happy and sad affective states induced by classical music. Hum Brain Mapp 28(11):1150-1162.

Mohanty A, Engels AS, Herrington JD, Heller W, Ho MH, Banich MT, et al. 2007. Differential engagement of anterior cingulate cortex subdivisions for cognitive and emotional function. Psychophysiology 44(3):343-351.

Morgan C, Bedford N, Rossell SL. 2006. Evidence of semantic disorganisation using semantic priming in individuals with high schizotypy. Schizophr Res 84(2-3):272-280.

Morgan CJ, Bedford NJ, O'Regan A, Rossell SL. 2009. Is semantic processing impaired in individuals with high schizotypy? J Nerv Ment Dis 197(4):232-238.

Nelson HE, Wilson J. 1991. National Adult Reading Test Manual. Windsor: NFER-Nelson.

Nestler EJ, Carlezon WA Jr. 2006. The mesolimbic dopamine reward circuit in depression. Biol Psychiatry 59(12):1151-1159.

Nowicka A, Marchewka A, Jednorog K, Tacikowski P, Brechmann A. 2010. Forgetting of Emotional Information Is Hard: An fMRI Study of Directed Forgetting. Cereb Cortex 21(3):539-549.

Ochsner KN, Gross JJ. 2005. The cognitive control of emotion. Trends Cogn Sci 9(5):242-249.

Park IH, Park HJ, Chun JW, Kim EY, Kim JJ. 2008. Dysfunctional modulation of emotional interference in the medial prefrontal cortex in patients with schizophrenia. Neurosci Lett 440(2):119-124.

Park JY, Gu BM, Kang DH, Shin YW, Choi CH, Lee JM, Kwon JS. 2010. Integration of cross-modal emotional information in the human brain: an fMRI study. Cortex 46(2):161-169.

Pessoa L. 2008. On the relationship between emotion and cognition. Nat Rev Neurosci 9(2):148-158.

Polli FE, Barton JJ, Thakkar KN, Greve DN, Goff DC, Rauch SL, Manoach DS. 2008. Reduced error-related activation in two anterior cingulate circuits is related to impaired performance in schizophrenia. Brain 131(Pt 4):971-986.

Pyka M, Beckmann CF, Schoning S, Hauke S, Heider D, Kugel $\mathrm{H}$, et al. 2009. Impact of working memory load on FMRI resting state pattern in subsequent resting phases. PLoS One 4(9):e7198. 


\section{P. Premkumar et al.}

Rama P, Martinkauppi S, Linnankoski I, Koivisto J, Aronen HJ, Carlson S. 2001. Working memory of identification of emotional vocal expressions: an fMRI study. Neuroimage 13(6 Pt 1):1090-1101.

Raune D, Kuipers E, Bebbington PE. 2004. Expressed emotion at first-episode psychosis: investigating a carer appraisal model. Br J Psychiatry 184:321-326.

Rosenfarb IS, Goldstein MJ, Mintz J, Nuechterlein KH. 1995. Expressed emotion and subclinical psychopathology observable within the transactions between schizophrenic patients and their family members. J Abnorm Psychol 104(2):259-267.

Rylands AJ, McKie S, Elliott R, Deakin JF, Tarrier N. 2011. A functional magnetic resonance imaging paradigm of expressed emotion in schizophrenia. J Nerv Ment Dis 199(1): 25-29.

\section{Supplementary material available online}

Examples of relative criticism, positive comment and neutral comment.
Sajonz B, Kahnt T, Margulies DS, Park SQ, Wittmann A, Stoy $\mathrm{M}$, et al. 2010. Delineating self-referential processing from episodic memory retrieval: common and dissociable networks. Neuroimage 50(4):1606-1617.

Vaughn C, Leff J. 1976. The measurement of expressed emotion in the families of psychiatric patients. Br J Soc Clin Psychol 15(2):157-165.

Vollema MG, van den Bosch RJ. 1995. The multidimensionality of schizotypy. Schizophr Bull 21(1):19-31.

Wager TD, Davidson ML, Hughes BL, Lindquist MA, Ochsner KN. 2008. Prefrontal-subcortical pathways mediating successful emotion regulation. Neuron 59(6):1037-1050.

Watson D, Clark LA, Tellegen A. 1988. Development and validation of brief measures of positive and negative affect: The PANAS scales. J Pers Soc Psychol 54(6):1063-1070. 
Copyright of World Journal of Biological Psychiatry is the property of Taylor \& Francis Ltd and its content may not be copied or emailed to multiple sites or posted to a listserv without the copyright holder's express written permission. However, users may print, download, or email articles for individual use. 